\title{
On the Relation between Solar and Global Volcanic Activities
}

\author{
Dhani Herdiwijaya \\ Astronomy Research Division and Bosscha Observatory, \\ Bandung Institute of Technology, \\ Bandung, Indonesia 40312 \\ e-mail: dhani@as.itb.ac.id \\ Johan Arif \\ Applied Geology Research Division, \\ Bandung Institute of Technology, \\ Bandung, Indonesia 40312 \\ M. Zamzam Nurzaman \\ Astronomy Graduate Program, \\ Bandung Institute of Technology, \\ Bandung, Indonesia 40312
}

\begin{abstract}
Solar activities eject high energetic particles, instead of electromagnetic radiation. The well-know solar activity main indicator is the existence of sunspot which has mean variation in 11 years, named by solar cycle. Solar activities are related to the space weather affecting all planets atmospheric variability, moreover to the Earth's climate variability. The big question arises to the relation between solar forcing energy to the Earth's global volcanic activities. We search its connectivity from yearly volcanic activities refer to Volcano Explosive Index (VEI) and sunspot number within year of 1900 to 2013 (113 years) which represent the global warming period and the range of Maunder minimum within year of 1615 to 1751 (136 years) which known as the global cooling period. We found that the declining solar cycle significantly show more volcanic activities (VEI=1 to 5) with more than $40 \%$ occurrences for both warming and cooling periods. They have mean occurrences of $(50.1 \pm 4.5) \%$ and $(42.0 \pm 10.4) \%$, respectively. In the rising phase of solar cycle, the average occurrences are $(27.1 \pm 3.3) \%$ and $(28.8 \pm 5.3) \%$, respectively. When we selected the interval time in 3 years around the peak of maximum and minimum of the solar cycle, the global warming period had average of $(27.1 \pm 5.5) \%$ and $(32.1 \pm 4.4) \%$, respectively and the global cooling period showed an average of $(32.7 \pm 11.1) \%$ and $(21.3 \pm 5.0) \%$, respectively. The minimum phase showed higher frequency events of volcanic activity than the maximum phase during the warming period, opposite to the cooling period. Although the physical reason is far for explanation, we argue that solar activities have a clear relation with global volcanic activities.
\end{abstract}

Keywords-Solar activities, Volcano Explosive Index (VEI), Volcano activities.

\section{INTRODUCTION}

The best contrast of solar surface features are sunspot group. The ancient researchers have documented their observation results personally or institutional. After data reconstruction, it is known of having regular mean periodicity of around 9.5 to 11 years. The sunspot number is defined and computed by the summation of observed daily individual sunspot and sunspot group [1]. Then, we called it solar activity index. The sunspot number or Wolf sunspot number was collected by researchers over 400 years. Instead of cyclic variation, they also found spotless periods or no visual or a few sunspot across solar surface for several years continuously. One of them was called Maunder Minimum, also known as the prolonged spotless period for the period starting in about 1645 and continuing to about 1715 [1]. This was not due to a lack of observations. The Maunder Minimum coincided with the middle part of the Little Ice Age, during which UK, Europe and North America were subjected to harsh cold winters. The global average temperature during that period was cooled by $0.3^{\circ} \mathrm{C}$ to $0.4^{\circ} \mathrm{C}$. However, regional drop temperature changes were quite large $\left(1^{\circ} \mathrm{C}\right.$ to $\left.2^{\circ} \mathrm{C}\right)$ [2]. On the other hand, in the last 100 years, solar activity or sunspot number have been increased by a factor of 2.3 [3] which represents as global warming period. From 1880 to 1990 the global mean annual temperature increased $0.55^{\circ} \mathrm{C}$ [4]. Until now, we do not yet know quantitatively how such changes in solar activities and how they will influence the global environment [5].

On the other phenomena, the hazardous geological event contains evidence of rare, explosive volcano super eruptions that have covered whole continents with volcanic ash and have global long-term recurrence intervals estimated to be in the range of 100,000-200,000 years. Basic geographic and geologic information for volcanoes thought to have been active in the last 10,000 years (Holocene) were recorded [6]. Other institutions are routinely updated the world volcano eruptions. More than 1,546 recently active volcanoes listed by the Smithsonian Institute Global Volcanism Program (GVP). Some were associated with major earthquake. The Volcanic Explosivity Index, or VEI, was proposed in 
1982 as a way to describe the relative size or magnitude of explosive volcanic eruptions [7]. It is a 0 to 8 index of increasing explosivity. Each increase in number represents an increase around a factor of ten. The VEI uses several factors to assign a number, including volume of erupted pyroclastic material (for example, ash fall, pyroclastic flows, and other ejecta), height of eruption column, duration in hours, and qualitative descriptive terms.

Some early results had been proposed for a possible global volcanic eruption cycle in relation with solar activity [8-10]. Unfortunately, there is no positive agreement for such correlations. Some authors have led to deny or agree any correlation between global volcanic eruptions and solar activity [11]. Moreover, there is no clear physical mechanism to explain any positive correlation. Conclusions were based merely on epoch analysis and simple visual inspection of tables or graphs. Further complete statistical tests of significance and multi-variables correlation should be performed to support the claimed presence of their any relationship.

In this study, we selected world volcanic eruption in the years of global cooling and global warming periods in order to study their relation to extreme condition of solar activities with terrestrial phenomena.

\section{DATA}

Annual mean sunspot data were compiled by Royal Observatory of Belgium. The yearly average sunspot number is obtained by taking the average of all daily numbers for the corresponding year. For years before 1849 and in particular before the 19th century, the annual mean becomes more approximate, when daily spotless Sun happened or sunspot counts were not available every day i.e. seasonal effects. For that period, the yearly average was then often obtained by averaging the monthly means.

In GVP catalog, eruptions have been classified according to a semi quantitatively based Volcanic Explosivity Index or VEI with a scale of VEI $=0$ for very small effusive eruptions to $\mathrm{VEI}=8$ for the largest explosive eruptions. Rankings of eruptions by VEI are usually uncertain for all, but the largest and best documented cases. In a small number of cases, the day or even the month of the eruption is ambiguous since the activity consisted of a closely spaced succession of large eruptions. Relative completeness of the dates only begins around 1800 for $\mathrm{VEI} \geq 5$, around 1900 for $\mathrm{VEI}=4$, and around 1960 for VEI $=3$. The progressive improvement in observing and reporting the smaller eruptions may influence the number of VEI, not really an actual increase of worldwide volcanism, especially in the last 200 years.

\section{RESULTS AND DISCUSSION}

\section{A. Sunspot Number}

Table 1 shows the solar cycle during the period from year 1600 to 2013 [12]. We can directly compare the sunspot number during solar very low activity or Maunder Minimum in year 1645 to 1715 and solar high activity in year 1900 to 2013. There is no unique cycle and several asymmetries occur in solar cycle phase (see Table I). Some study

mentioned that the last solar cyle (cycle 24) will be a lower peak to peak than the previous cycle.

The years of solar maximum and minimum phase and their sunspot number are seen in Table 1. The numbering of solar cycle is started in year 1755 . We can obtain that duration of rising phase and declining phase of solar cycle are different. The former is shorter than the latter. So, duration of each cycle or cycle length varies for each other. The higher sunspot number corresponds to shorter cycle length, vice-versa.

TABLE I. SOLAR CYCLE PHASE WITH CYCLE NUMBER, MAXIMUM AND MINIMUM SUNSPOT NUMBER

\begin{tabular}{|c|c|c|c|c|}
\hline $\begin{array}{c}\text { Solar } \\
\text { Cycle } \\
\text { Number }\end{array}$ & $\begin{array}{c}\text { Year of } \\
\text { Minimum }\end{array}$ & $\begin{array}{l}\text { Sunspot } \\
\text { Number }\end{array}$ & $\begin{array}{c}\text { Year of } \\
\text { Maximum }\end{array}$ & $\begin{array}{l}\text { Sunspot } \\
\text { Number }\end{array}$ \\
\hline- & 1610.8 & - & 1615.2 & 151 \\
\hline- & 1619.0 & 0 & 1626.0 & 61.5 \\
\hline- & 1634.0 & 0 & 1639.0 & 108.1 \\
\hline- & 1645.0 & 0 & 1649.0 & 0 \\
\hline- & 1655.0 & 0 & 1660.5 & 5.8 \\
\hline - & 1666.0 & 0 & 1676.8 & 7 \\
\hline - & 1679.5 & 0 & 1686.0 & 5.2 \\
\hline- & 1689.5 & 0 & 169350 & 1.5 \\
\hline- & 1698.0 & 0 & 1705.5 & 12.6 \\
\hline - & 1712.0 & 0 & 1719.5 & 64.5 \\
\hline- & 1723.5 & 0 & 1728.2 & 86.7 \\
\hline - & 1734.0 & 0 & 1739.7 & 121 \\
\hline - & 1745.0 & - & 1750.3 & 92.6 \\
\hline 1 & 1755.2 & 8.4 & 1761.5 & 86.5 \\
\hline 2 & 1766.5 & 11.2 & 1769.7 & 115.8 \\
\hline 3 & 1775.5 & 7.2 & 1778.4 & 158.5 \\
\hline 4 & 1784.7 & 9.5 & 1788.1 & 141.2 \\
\hline 5 & 1798.3 & 3.2 & 1805.2 & 49.2 \\
\hline 6 & 1810.6 & 0.0 & 1816.4 & 48.7 \\
\hline 7 & 1823.3 & 0.1 & 1829.9 & 71.7 \\
\hline 8 & 1833.9 & 7.3 & 1837.2 & 146.9 \\
\hline 9 & 1843.5 & 10.5 & 1848.1 & 131.6 \\
\hline 10 & 1856.0 & 3.2 & 1860.1 & 97.9 \\
\hline 11 & 1867.2 & 5.2 & 1870.6 & 140.5 \\
\hline 12 & 1878.9 & 2.2 & 1883.9 & 74.6 \\
\hline 13 & 1889.6 & 5.0 & 1894.1 & 87.9 \\
\hline 14 & 1901.7 & 2.6 & 1907.0 & 64.2 \\
\hline 15 & 1913.6 & 1.5 & 1917.6 & 105.4 \\
\hline 16 & 1923.6 & 5.6 & 1928.4 & 78.1 \\
\hline 17 & 1933.8 & 3.4 & 1937.4 & 119.2 \\
\hline 18 & 1944.2 & 7.7 & 1947.5 & 151.8 \\
\hline 19 & 1954.3 & 3.4 & 1957.9 & 201.3 \\
\hline 20 & 1964.9 & 9.6 & 1968.9 & 110.6 \\
\hline 21 & 1976.5 & 12.2 & 1979.9 & 164.5 \\
\hline 22 & 1986.8 & 12.3 & 1989.6 & 158.5 \\
\hline 23 & 1996.9 & 8.8 & 2000.3 & 120.8 \\
\hline 24 & 2008.9 & 1.7 & & \\
\hline
\end{tabular}




\section{B. Volcanic Explosivity Index}

From Table II, there was no eruption with VEI equal to 7 and 8. Only a very small number of eruption with VEI equal to 6. So, we only consider the VEI number $\leq 5$ in both cooling and warming periods. A VEI of 2 has served largely in number. Early numbers of VEI or minor phenomena act as precursors or after effects of major eruptions. However, we try to include for this study, although eruptions with VEI $\geq 3$ might be more useful to differentiate large eruptions.

TABLE II. THE TOTAL NUMBER OF VEI DURING THE COOLING PERIOD (1600 - 1751) AND WARMING PERIOD (1899-2013)

$\begin{array}{lll}\text { VEI } & \mathbf{1 6 0 0 - 1 7 5 1} & \mathbf{1 8 9 9 - 2 0 1 3} \\ 0 & 163 & 815 \\ 1 & 34 & 1010 \\ 2 & 277 & 1863 \\ 3 & 116 & 394 \\ 4 & 31 & 65 \\ 5 & 13 & 9 \\ 6 & 2 & 3 \\ 7 & 0 & 0 \\ 8 & 0 & 0 \\ \text { Total } & 636 & 4159\end{array}$

\section{Relation between VEI and Solar Cycle}

In Table III and Table IV, we separate the components of solar cycle into different phase. The minimum or maximum phases mean one year before to one year after the year of minimum or maximum, respectively. The rising period means the length from minimum to maximum phase. On the other hand, the falling phase is duration from maximum dan minimum phase. The length of falling period is usually longer than rising period. Duration of rising and falling years depend on year of minimum and maximum of the solar cycle or the length of solar cycle, as seen in Table I.

TABLE III. PROCENTAGE FOR RELATION OF VEI WITH SOLAR CYCLE PHASE IN COOLING PERIOD

\begin{tabular}{lllll}
\multicolumn{1}{c}{ VEI } & Min & Max & Rise & Fall \\
0 & 17.8 & 32.5 & 28.8 & 38.7 \\
1 & 29.4 & 14.7 & 32.4 & 52.9 \\
2 & 21.7 & 29.6 & 36.5 & 39.4 \\
3 & 24.1 & 32.8 & 29.3 & 41.4 \\
4 & 19.4 & 48.4 & 22.6 & 25.8 \\
5 & 15.4 & 38.5 & 23.1 & 53.8 \\
Average & 16.0 & 32.7 & 28.8 & 42.0 \\
Std. dev. & 10.7 & 11.1 & 5.3 & 10.4
\end{tabular}

During the declining phase, the average frequency of eruption is significantly larger in falling phase than the rising phase in both cooling and warming period. There is also indication that large eruptions occur in the low solar activity.

In cooling period, the maximum phase has a larger percentage in average of eruption and high intensity eruptions i.e. VEI $\geq 2$ than the minimum phase. In contrast with warming period, the minimum phase shows a larger percentage.

TABLE IV. PERCENTAGE FOR RELATION OF VEI WITH SOLAR CYCLE PHASE IN WARMING PERIOD

\begin{tabular}{lllll}
\multicolumn{1}{c}{ VEI } & Min & Max & Rise & Fall \\
0 & 30.9 & 26.7 & 27.4 & 51.0 \\
1 & 28.9 & 28.3 & 26.1 & 53.9 \\
2 & 26.1 & 29.3 & 28.1 & 51.3 \\
3 & 29.7 & 28.2 & 26.6 & 55.1 \\
4 & 32.3 & 16.9 & 32.3 & 44.6 \\
5 & 44.4 & 33.3 & 22.2 & 44.4 \\
Average & 32.1 & 27.1 & 27.1 & 50.1 \\
Std. dev. & 6.4 & 5.5 & 3.3 & 4.5
\end{tabular}

\section{CONCLUSION}

The Sun, interplanetary space, magnetosphere, ionosphere, the Earth's atmosphere, other geospheres, and the Earth itself with processes in its interiors, are an entire physical system, i.e., seismic and volcanic phenomena are parts of an integrated physical process in the Sun-EarthMoon system. Unfortunately, the obvious physical link between volcanic eruptions and solar activity can only be conjectured at present. Because of the large amount of randomness in the volcanic record, the link has a time delay in accumulating energy, and solar activity will acts for adding that energy. It is now fairly certain that the 11-year solar cycle has a finger print in changing of the Earth's climate, as indicated by measurements of surface pressure, temperature, precipitation, and zonal wind patterns. Those will cause a slight alteration of the Earth's total moment of inertia and of its atmospheric angular momentum. To conserve the Earth's total angular momentum, its interior rate of rotation adjusts. Fluctuations in the Earth's revolution should be searched for in interactions between the mantle and the core. It is established in geophysics that the core revolves relative to the mantle at about $0.2^{\circ}$ per year. The drift of the core and the intensification of its cyclic displacements are accompanied by elastic deformations of the mantle and respective abrupt changes of the stress and thermo dynamical state of all its layers. Instead of thermal and gravitational force, global electricity may also cause abrupt change in energy formation rate. The role of solar energetic particles i.e. cosmic ray, solar energetic proton and electron that will interact with magnetosphere, ionosphere and Earth's surface conductivity and resistivity could trigger seismic and earthquake activities. 
Although more study should be conducted with further multi-wavelength data, we concluded that during the declining phase, the average frequency of eruption is significantly larger in falling phase than the rising phase in both cooling and warming period. However, in cooling period, the maximum phase has a larger percentages in average of eruption and high intensity eruptions i.e. VEI $\geq 2$ than the minimum phase. In contrast with warming period, the minimum phase shows a larger percentage.

\section{ACKNOWLEDGMENT}

This work is supported by ITB Research Grant.

\section{REFERENCES}

[1] J.A. Eddy, "The Maunder Minimum," Science 192 (4245), pp. 1189 1202, June 1976

[2] D. T. Shindell, G. A. Schmidt, M. E. Mann, D. Rind, and A. Waple, "Solar forcing of regional climate change during the Maunder minimum," Science, vol. 294, pp. 2149-2152, December 2001.

[3] M. Lockwood, R. Stamper, and M. N. Wild, "A doubling of the Sun's coronal magnetic field during the past 100 years," Nature, vol. 399, pp. 437-439, June 1999.
[4] D.E. Parker, P.D. Jones, C.K. Folland, and A. Bevan,'Interdecadal changes of surface temperature since the late nineteenth century," J. Geophys. Res., vol. 99, pp. 14,373-14,399, July 1994

[5] M. Lockwood and M.J. Owens, "Implications of the recent low solar minimum for the solar wind during the Maunder minimum,” Astrophys. J. Lett., 781 (1), pp. L7, 2014.

[6] T. Simkin and L. Siebert, "Volcanoes of the world, a regional directory, gazeteer and chronology of volcanism during the last 10,000 years, “2nd edition, Geoscience Press Inc., Tucson, AZ. 1994.

[7] C.G. Newhall and S. Self, "The Volcanic Explosivity Index (VEI): An estimate of explosive magnitude for historical volcanism,“ J. Geophys. Res., vol. 87, pp. 1231-1238, February 1982.

[8] O'Reilly, J.P., "On the dates of volcanic eruptions and their concordance with the sunspot period, "Proc. R. Irish Acad., vol 5, pp. 392-432, 1899

[9] H.I. Jensen, "Possible relation between sunspot minima and volcanic eruptions, “J. R. Soc. N. S. W., vol. 36, pp. 42-60, 1902.

[10] K. Sapper, "Cycles of volcanic activity," Volcano Lett., vol. 302, pp. 2-4, 1930.

[11] J. Love and J. Thomas, "Insignificant solar-terrestrial triggering of earthquakes, " Geophysical Research Letters, vol. 40, pp. 1165-1170, March 2013.

[12] D.V. Hoyt and K. H. Schatten, "Group sunspot numbers: A New solar activity reconstruction," Solar Physics, vol. 181, pp. 491-512, August 1998. 